\title{
THE GENDER-BASED DIFFERENCE IN THE USE OF SPEECH ACTS OF REFUSAL: A STUDY OF THE KHOWAR LANGUAGE Abdul Saeed ${ }^{*}$, Shahzad Karim², Sajid Hussain ${ }^{3}$, Zakir Hussain ${ }^{4}$
}

1*Assistant Professor of English, Sukkur Institute of Business Administration University, Pakistan; ${ }^{2}$ Assistant Professor of English, The Islamia University of Bahawalpur, Pakistan; ${ }^{3}$ Assistant Professor of English, Karakoram International University Gilgit, Pakistan; ${ }^{4}$ M.A. English Linguistics, Karakoram International University Gilgit, Pakistan. Email: ${ }^{1 *}$ saeedabdulskr@gmail.com, ${ }^{2}$ shahzadaps@gmail.com, ${ }^{3}$ sajid.turi@kiu.edu.pk,

${ }^{4}$ zakirhussainshah902@gmail.com

Article History: Received on $18^{\text {th }}$ June 2021, Revised on $27^{\text {th }}$ June 2021, Published on $30^{\text {th }}$ June 2021

\section{Abstract}

Purpose of the study: Language, culture, and gender affect the ways one refuses an offer, suggestion, request, or invitation. Moreover, what we say and how we say may change the contextual meaning. Therefore, a study was conducted to examine the use of speech acts of refusal by the Khowar language speakers to know whether there is any gender difference.

Methodology: The undergraduate level students, aging between 15 and 25, participated in the study. An open-ended questionnaire was used for data collection. The questionnaire contained four hypothetical situations and each situation required the use of speech acts of refusal by the participants. A refusal classification format devised by Beebe (1990) was used to analyse the data.

Main Findings: The findings showed that both males and females used almost similar refusal strategies in all four situations. Direct and indirect refusal speech acts with pre-and post-refusal strategies were used in nearly the same quantity. The study also revealed that language, culture, and social status did not play an important role in realising refusal strategies.

Application of the study: The study will help linguists, language teachers, and anthropologists to understand the nature of male and female Khowar language speakers. It will also add valuable literature on the use of language and gender differences.

The originality of the study: The study is significant being the first of its kind that addressed the gender difference and language use in Khowar language speakers. The study is also vital as it will preserve a minor language spoken in one of the remotest areas of Pakistan.

Keywords: Speech Acts of Refusal, Pragmatics, Gender, Language Preservation, Direct and Indirect Speech Acts, Discourse Analysis.

\section{INTRODUCTION}

The distinction between 'sentence meaning' (the literal meaning of a sentence) and 'intended meaning' makes the modern linguists think that 'what is said is not enough to comprehend a message completely unless the aspect of 'how it is said' is also focused. The explanation for this is that words do not appear on their own; rather, they are combined with other linguistic features (such as tone, pitch, and stress), which make communication effective. This realization bifurcated grammatical competence (sentence meaning) from pragmatic competence (intended meaning). This is why during the last few decades, linguists have shifted their direction of research from grammatical theories of language learning to communicative learning studies (1-Zumor, 2003).

Major progress in this regard was made by Austin (1975), who propounded speech act theory. According to speech act theory, language is not just a tool to share information; instead, we perform many actions in our daily life through language/utterances. For example, we make promises and requests and refuse suggestions. Among these verbal actions, the speech act of refusal is deemed especially important as it involves the risk of face-threatening. The users of different languages practice different refusal strategies in line with their socio-linguistic norms to mitigate the face-threatening effect of refusals.

The difference in the use of refusal strategies is found in both inter and intra socio-linguistic contexts. For example, the difference in the use of refusal strategies may occur because of some other factors, such as age, relationship, and gender. Eckert (2019) indicates that due to the difference in nature (as women are more other-oriented and collaborative than men), women are more likely to use polite words than men. Baker (2013) asserts that women are shy and polite in speaking, whereas men are authoritative and power-seeker. Baker (2013) further says that, in general, the word 'women' is not considered as mature as the word 'men'. In the literature, we find many studies such as Giyoto et al. (2020) and Ang (2003); that have investigated the use of speech acts of refusal by different genders in different languages. However, we (the researchers) did not find even a single study that has investigated the gender-based difference in the use of speech acts of refusal in the Khowar language. Khowar is a language that is widely spoken in the northern mountainous region of Pakistan which includes the districts of Gilgit, Ghizer, and Chitral (more information about the Khowar language is given in the literature review section). Therefore, the present study was conducted to explore the 
gender-based difference in speech acts of refusal in the Khowar language. The study investigated the following research questions:

\section{Research questions}

1. Who (male or female speakers of the Khowar language) is more direct or indirect in speech acts of refusal in everyday conversation?

2. Is there any difference in the frequency of direct or indirect speech acts of refusal by male and female speakers of the Khowar language?

\section{LITERATURE REVIEW}

Austin (1975) propounded the theory of speech acts in his famous lectures titled 'How to do things with words. According to Kinginger (2011), speech acts are the functions and the communicative acts of the language which convey the intended meanings and intentions of the speakers in a language encounter. Searle (1975) identifies two types of speech acts: direct and indirect. Direct speech acts are the acts in which the meaning of the expression and the speaker's meaning or intended meaning are consistent. On the other hand, indirect speech acts are utterances that have no uniformity or connectedness between the sentence meaning and the speaker's intended meaning. In interlanguage pragmatics, many studies have been carried out in the framework of speech acts. Although it is presumed that speech acts are universal and all languages have means of executing speech acts, languages vary from culture to culture in terms of the form and structure used in specific speech acts (Wolfson, 1989). Among all speech acts, the speech act of refusal is deemed to be problematic and complex because it may involve a face-threatening effect.

\section{Speech acts of refusal}

Refusals are speech acts by which speakers deny engaging in an action proposed by the interlocutor(s) (Chen et al., 1995). These are characterized as responses in negation that occur in response to other speech acts, i.e., the speech acts of suggestion, request, offer, and invitation. It is important to note that unlike the other (above-mentioned) speech acts, a speech act of refusal does not occur in a language as an opening act itself. Refusal speech acts fall under the category of commissive speech acts because they commit the refuser to perform/not perform an action that may have a substantial possibility of having face-threatening. Therefore, the language speakers use specific cultural and linguistic expertise to refuse an act (Brown et al., 1987).

Speech acts of refusal are one of the important topics in Discourse Pragmatics. Studies conducted in the last several years have proven that pragmatics plays a significant role in interpreting many aspects of spoken actions of refuse. Speech acts of refusal are of great interest and importance as they are regularly used in different scenarios in our everyday life (Sahragard, 2011). Refusals are not simple in their construction as they are not direct; instead, they are often extended to a few turns. Yamagashira (2001) also notes that speakers use indirect communicative strategies while refusing to avoid any offensive act. For this, the speakers may try to use different forms in various refusal situations. There are four situations (i.e., request, offer, suggestion, or invitation) in response to which one has to refuse to the interlocutor. These situations are discussed in detail below.

\section{Refusal to request}

The speech act of request involves some favour on the part of the requested. It shows that the requester is dependent on the requested to follow the request. Thus, it entails more techniques and strategies on the part of the requested person to refuse the favour, as it contains a face-threatening act greater than any other speech act. So, the speakers of a language use different strategies, such as reasons, explanations, excuses, in declining requests to mitigate the face-threatening effect (Yang, 2008). However, these strategies may vary from culture to culture in both form and content (BardoviHarlig, 1993). For instance, in a low-context culture where most of the things are said explicitly, and focus is also given on non-verbal communication, such as American and European, people first give a positive statement about the requester followed by a statement of regret (I'm sorry), and then they finally give an excuse (Félix-Brasdefer, 2006). On the other hand, a high-context culture such as Iran, Pakistan, and India use a great deal of implied communication. People of these cultures mostly make an excuse which is followed by an expression of sorrow while refusing a request. This strategy helps them to mitigate the face-threatening effect (Sadeghi, 2011).

\section{Refusal to offers}

Like the refusal to the speech acts of request, people vary culture to culture and community to community in turning down an offer, such as accepting a gift, drink, or any other favour. Research shows that the people belonging to a highcontext culture tend to decline an offer implicitly, whereas the people belonging to a low-context culture deny an offer explicitly. Moreover, in a high-context culture, people least refuse an offer given by an elder person or by a person of a higher social status (Izadi, 2015).

\section{Refusal to suggestions}

Suggestions are the recommendations that are given by the addresser to the addressee to make the addressee act upon 
them. Suggestions are of two kinds: (i) solicited, and (ii) unsolicited. Solicited suggestions are given at the request of the requester, and thus, these are seldom turned down. On the other hand, unsolicited suggestions are given to the listener voluntarily, irrespective of whether they request them or not. So, the possibility of declining unsolicited suggestions is more. However, it also depends on the person and the context (Eslami, 2010).

\section{Refusal to invitations}

The invitation is quite common across cultures. According to Sadeghi (2011), invitations often occur by the end of the interaction. In such situations, the pragmatic purpose of the invitation is to get leave and bring the interaction to an end. Sadeghi (2011) made a comparison between the Americans and the Iranians in using refusal strategies. He found that the Americans used more direct strategies as compared to the Iranians. Further, when refusing, the Americans appeared to make no difference between the person of a higher or lower social status. On the other hand, the Iranians mostly appeared to make excuses while refusing to a person of higher social status (such as their bosses) as compared to the person of a lower or equal social status (such as their friends). According to Sadeghi (2011), this difference between the Americans and Iranians may be due to cultural differences, as the American culture is a low-context culture, whereas, the Iranian culture is predominantly a high-context culture where refusal is taken more seriously as compared to the American culture. Farnia (2012) conducted a study in which she compared the acts of refusal of invitation used by the Chinese and Malay students studying in Malaysia. Farnia (2012) found that the Chinese and Malay students used the acts of refusal of invitation differently.

\section{Gender difference}

Gender is a social phenomenon that is quite different from the sexual bifurcation of men and women (Dong, 2014). Gender treatment varies from society to society, depending upon their set social norms. For instance, European societies are different from those of Asians in their treatment of females. Moreover, even Asian countries differ in their treatment of females due to their specific cultural norms. Consequently, this dichotomy affects the use of language by males and females. Sachs (1987) studied young children of two-to-five-year to find out whether boys and girls start behaving like their adult male and female right from their childhood. He found that girls produced indirect and soft imperatives as is reported to be used by grown-up females. In contrast, boys spoke like grown-up males and used direct imperatives because males have more authority in society, and it is reflected in their speech.

Gire (1993) held the study to determine the difference between males and females in using conflict resolution. The participants of the study were university students from Canada and Nigeria. Findings showed that males were on the extreme in selecting the methods of conflict resolution. For example, most of them preferred the use of threats to resolve conflicts. On the other hand, females appeared to use polite strategies to resolve conflicts. Some other scholars, (such as.

Ang (2003) conducted a study to find out whether males and females use different refusal strategies. She studied 280 samples (140 for each gender) from the National University of Singapore with the 23-year average age for males and the 20 -year average age for females. The study explored the effects of culture on the directness of refusal. It was an intracultural study on refusal speech acts. The findings of the study showed that males use more direct strategies as compared to females. Based on the findings, the researcher claimed that culture is the basic element that affects speakers' choice of linguistic items and strategies.

Strong et al., (2009) studied gender differences in the use of describing retrospective pain. Participants were instructed to write a paragraph, describing any past unforgettable painful incident. The findings of the study revealed that the females were found using significantly different language. They made more use of concrete and sensory adjectives than males. They also differed in the length of the description. On average, the males used 56 adjectives, whereas the females used 84 adjectives. Moreover, males described more psychological pain, whereas females tend to express more physical pain.

Parvaresh et al., (2014) investigated the role of power in making different genders use language differently. Parvaresh et al., (2014) collected data from 110 Persian native male and female speakers. The study aimed to determine the difference in politeness strategies used by both genders when refusing a request. The females were found using more indirect strategies followed by expressions of regret, such as 'I am sorry', whereas the males directly refused the request. Parvaresh et al., (2014) concluded that culture and power have a strong influence on one's choice of linguistic items, and it is society, not language, which compels the speaker to select these choices.

Giyoto et al., 2020) have also reported differences concerning gender when using speech acts in response to conflicts and refusals. The research shows that males lead the conversation and use more direct refusals. In contrast, females use more indirect refusals and support it through a move-on-strategy, i.e. they wanted to carry on the discussion

\section{The Khowar language}

Khowar, which is also known as Chitrali (a name derived from Chitral), is spoken in Chitral, which is a district in Khyber Pakhtunkhwa, Pakistan. 'Kho' means cave, and 'War' means language. The initial settlers of Chitral were living in caves, as the landscape of Chitral is full of caves. So, Khowar is a language of people who lived in caves. The Khowar language has words from Sanskrit, Persian, Hindi, and Turkish languages. The roots of Khowar are from Turkish and Tartar languages, which have one base. A salient feature of the Turkish language is that its base has not changed so far, 
and it still exists in its original form. According to local historians and the oral traditions of the area, the 'Kho' people came to Chitral from Central Asia and Mongolia in the fifth and sixth centuries and settled in Chitral. Khowar is mainly used in the areas of Chitral, Ghizer, and Upper Swat in Pakistan. A great number of Khowar speakers have also migrated to Pakistan's major urban cities, such as Peshawar, Islamabad, Lahore, and Karachi. A small number of Khowar speakers are also believed to live in Afghanistan and Tajikistan as well.

\section{METHODOLOGY}

\section{Participants of the study}

The participants in this study were undergraduate level students studying in the local college in Ishkoman valley. Most of them were in the $3^{\text {rd }}$ and $4^{\text {th }}$ year of their study, and their ages ranged between 16 and 22 . A total of 60 students participated in the study. They were equally divided into male and female (30 males and 30 females), and they all belonged to the same ethnic group. All participants were native speakers of the Khowar language.

A Discourse Completion Test (DCT) was used to obtain the required data. The test is based on four different hypothetical or fictional settings, and these were formulated on equality/closeness, social distance, and relative power. An act of refusal from the participants was a prerequisite in all these situations. Blum-Kulka (1982) introduced DCT, and since then it has been employed by several researchers to obtain data for speech act realization studies. Some of these studies include Blum-Kulka (1982), Beebe, et al., (1990), Sattar et al., (2010). The present study is conducted by engaging an adapted version of DCT developed by Beebe et al., (1990).

\section{Data collection and analysis}

The data were collected by administering the questionnaires with the participants. For data collection, permission was obtained from the competent authority of the college. The participants participated in the study voluntarily. The participants were informed in detail about how to fill in the questionnaire. As the participants were not self-assured while writing in the Khowar language using Urdu alphabets, English alphabets were used to complete the task. The task of filling in the questionnaire took about an hour. As the participants responded to the Khowar language using English alphabets, the researcher codified all the participants' responses in English. The purpose of codification was to compare these responses with the classification format of Beebe et al. (1990) as it was available only in the English language. After the analysis, all valid responses by the participants were classified into direct and indirect refusal strategies.

\section{FINDINGS AND DISCUSSION}

Table 1 below shows the refusal strategies of the four hypothetical situations, which are based on various social parameters, i.e., closeness, distance, and equality. The table clearly shows the difference in the frequency of direct and indirect refusal strategies in all four situations. In situations 1 and 2, the participants are inclined towards using more indirect and less direct strategies, perhaps to save the face of the interlocutor. On the other hand, in situation 3 , the participants employed more direct strategies and less indirect strategies. In these three situations, minor gender difference appears in refusal strategies or speech acts of refusal. However, the gender difference is visible in situation 4, where males are inclined to use more direct strategies and females to use more indirect strategies.

Table 1: Refusal strategies for all four hypothetical situations

\begin{tabular}{llllllll}
\hline Situations & Social parameters & \multicolumn{2}{l}{ Refusal strategies by males } & \multicolumn{2}{l}{ Refusal strategies by females } \\
\hline & & $\mathrm{D}$ & $\mathrm{I}$ & $\mathrm{A}$ & $\mathrm{D}$ & $\mathrm{I}$ & $\mathrm{A}$ \\
\hline 1 & Social distance & 10 & 19 & 0 & 12 & 16 & 0 \\
\hline 2 & Equal status & 10 & 19 & 0 & 11 & 14 & 0 \\
\hline 3 & Social distance & 21 & 19 & 0 & 19 & 10 & 0 \\
\hline 4 & Equal status and closeness & 20 & 08 & 0 & 12 & 16 & 0 \\
\hline Total & & 61 & 65 & 0 & 54 & 56 & 0 \\
\hline
\end{tabular}

$\mathrm{D}=$ Direct, I=Indirect, $\mathrm{A}=$ Adjuncts

In terms of the individual situation, situation 1 compares the refusal to request strategies between male and female Khowar speakers. In this situation, younger siblings are asked by their elder brother to bring him a glass of water. Despite having social distance between the interlocutors, the participants of both groups used almost similar refusal strategies. Twelve female and ten male participants used direct refusal strategies. Female participants employed 'No' and performatives. On the other hand, male participants used 'No' negative willingness, negative ability, and performative. In contrast, sixteen females and nineteen male participants used indirect refusal strategies. Most of these strategies were realized by alternatives followed by reasons. In addition, some of them also used excuses and criticism. Nevertheless, both male and female participants did not employ adjuncts of refusal. Three responses were found invalid — two by female participants and one by a male participant.

In situation 1, participants used more indirect refusal strategies than direct ones. Yang (2008) states that reasons, excuses, alternatives, or explanations are the common strategies speakers use to refuse requests. Moreover, the head act position was constantly switching sometimes from initial to middle and final positions. Both groups did not employ 
adjuncts as well. The results also witnessed both genders using very similar direct and indirect refusal strategies, which shows little gender difference between the participants about the use of refusals. These findings are in line with Holtgraves (1997) and Maharani et al., (2020) as they also found little gender difference in request refusal situations in their respective studies. However, Rahmawati (2014) found females are more likely to use indirect refusal strategies than males. The frequency of direct and indirect refusal strategies employed by participants in this study is practically the same, and there is a slight margin in their recurrence. Subsequently, they are not inferable. The most commonly used strategies by both males and females are reasons, and they are used as pre and post refusal strategies in direct refusal strategies. In indirect refusals, head acts are used more frequently. To lessen the upcoming refusal, address terms (such as brother, dear brother) have been frequently used by the participants.

In situation 2, a class fellow is asking another fellow to lend him their book. Unlike situation 1, in situation 2, both interlocutors have a similar social status. Situation 2 compares the refusal to offer responses. Eleven females and ten males used direct refusal strategies, and most of these strategies featured the use of 'No' or negative ability. However, a few negative willingness and performative strategies were also incorporated. On the other hand, indirect refusal strategies were used by nineteen male and fourteen female participants. The participants mostly used reasons in these indirect strategies. Explanation, criticism, and alternatives were also used as indirect strategies. Address terms (such as dear fellow, dear friends) were employed by both male and female participants, although male and female participants did not use adjuncts as refusal strategies. One response by a male participant and five responses by female participants were invalid.

In situation 2, little gender difference is observed in terms of the frequency of various strategies, a semantic formula of strategy, and frequency of direct and indirect strategies. When we compare situation 1 with situation 2 , we find that the selection of linguistic expression of refusal strategies employed by the interlocutors has no concern with their social status. The frequency of using direct or indirect refusal strategies was almost similar, despite having a difference in the social status of the interlocutors in both situations. Houck (2011) found that nearly two-thirds of the total responses were based on the statement of regret, non-performative refusal, excuse, alternative, and reason. However, neither female nor male participants used adjunct as a refusal strategy.

Through situation 3 (in which an instructor suggests the participants accompany them for a day tour), participants' responses in the form of refusal to the given suggestions are compared. In this situation, participants used more direct refusal strategies than indirect ones. Nineteen female and twenty-one male participants employed direct refusal strategies using the negative ability, whereas 'No', negative willingness, performatives, and other direct strategies were employed in a small number by both genders. In contrast, ten females and nine male participants employed indirect refusal strategies. In indirect refusal, reasons were widely used as a strategy by the participants. Contrary, excuses, and explanations were used by a few participants as indirect refusal strategies. Not a single instance of adjunct as a refusal strategy was used by the participants. One response by a female participant was found invalid. Both groups used similar terms (such as Sir, Madam, Dears Sir) to address. The gender and social status of the participants appeared to have less effect upon the selection of the strategies. The findings of the present study are similar to those of Félix-Brasdefer (2006), who reports that to reduce the potential threats and danger due to refusal acts, reason and explanation strategies are employed frequently.

Situation 4 compares refusal to invitation strategies. In this situation, few friends get an invitation from a friend to attend a wedding ceremony. This hypothetical situation represents a social status of equality and closeness. Similar to situation 3 , in situation 4, the participants made more use of direct refusal strategies than indirect refusal strategies. 12 female and 20 male participants employed negative ability as a direct refusal strategy, whereas some of them employed 'No' and performatives. In contrast, indirect refusal strategies were employed by sixteen females and eight male participants. The most frequently used indirect refusal strategies were 'reasons'. However, 'excuses' and 'explanations' were also used by some participants. These findings of our study are similar to the findings of Beebe et al., (1990) that 'reason' and 'explanation' are frequently incorporated in refusal responses. Both groups of participants did not employ adjuncts. A small number of participants also used address terms, such as a dear, dear friend.

\section{CONCLUSION AND RECOMMENDATIONS}

The main purpose of the study was to investigate the gender-based difference in the use of refusal strategies by Khowar speakers. Findings revealed an insignificant gender difference between male and female speakers of the Khowar language while employing refusal strategies. In addition, very little gender difference was found in terms of using direct and indirect pre and post refusal strategies. Hence, it can be safely concluded that the interlocutors' gender and social status did not play a significant role in the realization of refusal strategies.

\section{LIMITATION AND STUDY FORWARD}

The present study used a questionnaire with four hypothetical situations. Future studies can use role-plays and refusals in a natural situation, which may provide different and interesting findings. This research was based on an intra-cultural language study, future studies can be carried out by comparing different cultures and languages. 


\section{ACKNOWLEDGEMENT}

This research paper is an outcome of the authors' research interests. It received no specific grant from any funding agency in the public, commercial, or not-for-profit sectors. We would like to thank all the independent reviewers of HSSR for their valuable comments and suggestions.

\section{AUTHORS CONTRIBUTION}

Dr. Abdul Saeed: Worked on the conceptual framework, introduction, and literature review. Dr. Shahzad Karim: Wrote methodology, data analysis, and conclusion. Sajid Hussain: Thoroughly reviewed the paper, improved the academic writing style of the paper, and reviewed the paper according to APA style of referencing. Zakir Hussain: Transcribed all Khowar speakers' responses into English.

\section{REFERENCES}

1. Al-Zumor, A. (2003). A pragmatic analysis of speech acts as produced by native speakers of Arabic. (Unpublished doctoral thesis). Aligarh Muslim University. http://ir.amu.ac.in/id/eprint/3078

2. Ang, R. P., \& Kuo, E. C. (2003). Effects of gender and individualism-collectivism on directness of refusal. South Pacific Journal of Psychology, 14, 76-80. https://doi.org/10.1017/S0257543400000262

3. Austin, J. L. (1975). How to do things with words. Oxford University Press. https://doi.org/10.1093/acp rof:oso/9780198245537.001.0001

4. Baker, P. (2013). Introduction: Virtual special issue of gender and language on corpus approaches. Gender and Language, 1(1), 4-22. https://doi.org/10.1558/8psxqda5wh3d

5. Bardovi-Harlig, K., \& Hartford, B. S. (1993). Learning the rules of academic talk: A longitudinal study of pragmatic change. Studies in Second Language Acquisition, 15(3), 279-304. https://doi.org/10.1017/S 0272263100012122

6. Beebe, L. M., Takahashi, T., \& Uliss-Weltz, R. (1990). Pragmatic transfer in ESL refusals. In E. S. Andersan. and S. D. Krashen (Ed.), Developing communicative competence in a second language (pp. 55-73). Newbury House Publishers.

7. Blum-Kulka, S. (1982). Learning how to say what you mean in a second language: A cross-cultural study of Hebrew and English. Applied Linguistics, 3(1), 29-59. https://doi.org/10.1093/applin/3.1.29

8. Brown, P., \& Levinson, S. C. (1987). Politeness: Some universals in language usage. Cambridge University Press. https://doi.org/10.1017/CBO9780511813085

9. Chen, X., Ye, L., \& Zhang, Y. (1995). Refusing in Chinese. In G. Kasper (Ed.), Pragmatics of Chinese as native and target language (pp. 119-163). University of Hawaii Press.

10. Dong J. Y (2014). Study on gender differences in language under the sociolinguistics. Canadian Social Science, 10(3), 92-96.

11. Eckert, P. (2019). The limits of meaning: Social indexicality, variation, and the cline of interiority. Language, 95(4), 751-776. https://doi.org/10.1353/lan.2019.0072

12. Eslami, Z. R. (2010). How to develop appropriate refusal strategies. In A. Martinez Flor, Uso Juan, E. (Ed), Speech act performance: Theoretical, empirical and methodological issues (pp. 217-236). John Benjamins Amsterdam/Philadelphia. https://doi.org/10.1075/11lt.26.13esl

13. Farnia, M., \& Wu, X. (2012). An intercultural communication study of Chinese and Malaysian university students' refusal to invitation. International Journal of English Linguistics, 2(1), 162-176. https://doi.org/10.55 39/ijel.v2n1p162

14. Félix-Brasdefer, J. C. (2006). Linguistic politeness in Mexico: Refusal strategies among male speakers of Mexican Spanish. Journal of Pragmatics, 38(12), 2158-2187. https://doi.org/10.1016/j.pragma.2006.05.004

15. Gire, J. T., \& Carment, D. W. (1993). Dealing with disputes: The influence of individualism-collectivism. The Journal of Social Psychology, 133(1), 81-95. https://doi.org/10.1080/00224545.1993.9712121

16. Giyoto, G., Anggraini, N., Inderasari, E., \& Purnomo, L. A. (2020). How does "To what gender and status one talks" govern the speaker's strategy in keeping on their conversation? Journal of Language and Linguistic Studies, 16(1), 166-184. https://doi.org/10.17263/j1ls.712691

17. Holtgraves, T. (1997). Styles of language use: Individual and cultural variability in conversational indirectness. Journal of Personality and Social Psychology, 73(3), 624-637. https://doi.org/10.1037/0022-3514.73.3.624

18. Houck, N., \& Gass, S. M. (2011). Interlanguage refusals: A cross-cultural study of Japanese-English. Walter de Gruyter.

19. Izadi, A., \& Zilaie, F. (2015). Refusal strategies in Persian. International Journal of Applied Linguistics, 25(2), 246-264. https://doi.org/10.1111/ijal.12065

20. Kinginger, C., \& G. Schauer (2011). Interlanguage pragmatic development: The study abroad context. Applied Linguistics, 32(5), 572-574. https://doi.org/10.1093/applin/amr033

21. Maharani, S., Mujiyanto, J., \& Warsono, W. (2020). The Relations between male and female participants in using assertive speech acts for interactions in The Ellen DeGeneres Show. English Education Journal, 10(2), 234-241.

22. Parvaresh, H. R., Bidaki, T., \& Farahani, A. A. K. (2014). Refusal strategies of Iranian EFL learners: The role 
of sex, age, education levels, and politeness. International Journal of Education and Applied Sciences, 1(3), 121-128.

23. Rahmawati, L. (2014). Gender differences in indirect asking for information in Hitam Putih and Sarah Sechan Talk Shows. Jurnal Ilmiah Mahasiswa FIB, 4(8).

24. Sachs, J. (1987). Preschool boys' and girls' language use in pretend play. In S. U. Philips, S. Steele, \& C. Tanz (Ed.), Language, gender, and sex in comparative perspective (pp. 178-188). Cambridge University Press Cambridge. https://doi.org/10.1017/CBO9780511621918.009

25. Sadeghi, K., \& Savojbolaghchilar, S. (2011). A comparative study of refusal strategies used by Iranians and Americans. International Journal of Academic Research, 3(2), 601-606.

26. Sahragard, R., \& Javanmardi, F. (2011). English speech act realization of 'Refusals' among Iranian EFL learners. Cross-Cultural Communication, 7(2), 181-198.

27. Sattar, H. Q. A., Lah, S. C., \& Suleiman, R. R. R. (2010). A study on strategies used in Iraqi Arabic to refuse suggestions. The International Journal of Language Society and Culture, 30, 81-95.

28. Searle, J. R. (1975). Indirect speech acts. In P. Cole \& J. Morgan (Ed.), Syntax and Semantics: speech acts (pp. 59-82). Academic Press. https://doi.org/10.1163/9789004368811_004

29. Strong, J., Mathews, T., Sussex, R., New, F., Hoey, S., \& Mitchell, G. (2009). Pain language and gender differences when describing a past pain event. PAIN, 145(1-2), 86-95. https://doi.org/10.1016/j.p ain.2009.05.018

30. Wolfson, N. (1989). Perspectives: Sociolinguistics and TESOL. Newbury House Publishers.

31. Yamagashira, H. (2001). Pragmatic transfer in Japanese ESL refusals. Kagoshima Immaculate Heart College. English Department, 31, 259-275. http://id.nii.ac.jp/1158/00000531

32. Yang, J. (2008). How to say 'no' in Chinese: A pragmatic study of refusal strategies in five TV series. Proceedings of the 20th North American Conference on Chinese Linguistics, 2, 1041-1058.

\section{APPENDIX - A}

Translation of Khowar refusal strategies into English

\section{Example of a refusal strategy by a male participant}

A suggestion/offer by a friend:

Ahmad: Gye la dust bazarot bisi

English Translation: Let us go to bazaar.

Hamid: Ay awa gik no bom la ma dura kmro korum shair

English Translation: I could not come with you, as I have a little business at home.

\section{Example of a refusal strategy by a female participant}

A suggestion/offer by a friend:

Saleema: "Ay time ki shair ma durot gyeki kya korum shair"

English Trans: If you have time, come to me please. I have a little business with you.

Rehana: "Ay no la ma dura ka di neki”

English Trans: O no dear, there is no one at my home. 